\title{
Modelling of optimal energy flows for systems with close integration of sea water desalination and renewable energy sources: case study for Jordan
}

Luka Perkovići ${ }^{* a}$, Tomislav Novosel $^{a}$, Tomislav Pukšec ${ }^{a}$, Boris Ćosića, Manal Mustafab ${ }^{b}$ Goran Krajačića, Neven Duića

a University of Zagreb, Faculty of Mechanical Engineering and Naval Architecture, Department of Energy, Power Engineering and Environment, Ivana Lučića 5, 10002 Zagreb, Croatia

${ }^{\mathrm{b}}$ Hashemite University, Department of Mechanical Engineering, Zarqa, Jord an

\begin{abstract}
This paper presents a new approach for modelling energy flows in complex energy systems with parallel supply of fresh water and electricity. Such systems consist of renewable energy sources (RES), desalination plant, conventional power plants and the residual brine storage which is used as energy storage. The presented method is treating energy vectors in the system as control variables to provide the optimal solution in terms of the lowest critical excess of electricity production (CEEP) and $h$ ighest possible share of RES in the supply mix. The optimal solution for supplying the demands for fresh water and electricity is al ways found within the framework of model constraints which are derived from the physical limitations of the system. The presented method enables the optimization of energyflows for a larger period of time. This increases the role of energy storage when higher integration of RES in the supply mix. The method is tested on a hypothetical case of Jordan for different levels of installed wind and PV capacities, as well as different sizes of the brine storage. Results show that increasing the optimization horizon from one hour to 24 hours can reduce the CEEP by $80 \%$ and allow the increase of RES in the supply mix by more than $5 \%$ without violating the CEEP threshold limit of $5 \%$. The activity of the energy (brine) storage is crucial for achieving this goal.
\end{abstract}

\footnotetext{
*Corresponding author; email: luka.perkovic@fsb.hr; tel. +38516168494
} 


\section{Keywords}

Optimal energy flows; renewable energy sources (RES); desalination plant; energy storage; critical excess of electricity production (CEEP) 


\section{Research highlights}

- a new methodology for optimal management of energy systems is proposed

- critical excess of electricity production is reduced by optimizing the energy flows

- at the same time, the curtailment from the RES can be decreased 


\section{Nomenclature}

$a_{t}^{i} \quad$ vector of specificcosts for each control variable $i$ for time step $t$

(cost $\left./ \mathrm{kWh}, \operatorname{cost} / \mathrm{m}^{3}\right)$

$e_{t}^{i} \quad$ control variable $i$ for time step $t$

$\left(\mathrm{kWh}, \mathrm{m}^{3}\right)$

$f \quad$ objective function

(cost)

$F_{\text {stab }}$ grid stabilization factor

$X^{D E S}$ desalination plant energy consumpt. per $\mathrm{m}^{3}$ of fresh water

$\left(\mathrm{kWh} / \mathrm{m}^{3}{ }_{\mathrm{FW}}\right)$

$X^{B} \quad$ desalination plant efficiency

$\left(\mathrm{m}^{3}{ }_{\mathrm{B}} / \mathrm{m}^{3}{ }_{\mathrm{RS}}\right)$

$K^{P} \quad$ linear coefficient energy-mass flow

$(\mathrm{kWh} / \mathrm{kg} / \mathrm{h})$

$v_{t}^{j} \quad$ volume flow for quantity $j$ in time step $t$

$\left(\mathrm{m}^{3} / \mathrm{h}\right)$

$D_{t}^{F W}$ demand for fresh water in time step $t$

$\left(\mathrm{m}^{3} / \mathrm{h}\right)$

$D_{t}^{E L} \quad$ demand for electricity in time step $t$

(kW)

$\delta_{t}^{j} \quad$ hourly distribution of RES quantity $j$

$S_{t}^{j} \quad$ storage level for quantity $j$ in time step $t$

$\left(\mathrm{Mm}^{3}\right)$

$\bar{S}^{j} \quad$ maximum storage level for quantity $j$

$\left(\mathrm{Mm}^{3}\right)$

$P \quad$ power

$t \quad$ time step

$T \quad$ optimization horizon time for elliptic optimization

$T^{B r} \quad$ time for which brine storage has to provide turbining power at max. capacity

$X_{\%}^{j} \quad$ level of energy penetration for RES quantity $j$ as a percentage of the total demand(\%) 


\section{Superscripts}

W wind

PV photovoltaic

$\mathrm{Br} \quad$ brine

DS Dead sea

C conventional

EL electricity

RS Red sea

DES desalination

P pumping

T turbining

tot total

spill brine spilled into the brine reservoir

CEEP Critical Excess of Electricity Production

\section{Introduction}

A heavy dependence on fossil fuels and severe water scarcity are common issues in a number of arid countries and regions. At the same time, these countries have sufficient renewable potential for sustainable desalination [1]. Direct use of RES in desalination is currently used only in satisfying lower 
demands in rural off-grid areas [2], [3], [4], but application on bigger areas has recently been investigated [2], [5]. In literature there are many papers dealing with sustainable desalination [6] and more efficient desalination process, like the role of thermal and electrical storages in RES-driven desalination process [7], thermo economic optimization [8], optimization of flow patterns [9], use of low-grade heat source for powering the desalination unit [10] or modelling of energy systems with close integration of renewables and desalination [11], [4], [12], [13]. Since one of the residues of the desalination process is brine, a brine reservoir is needed in the system. Brine can also be used as a medium for pumped storage, as already presented in [11], [14], [15]. Management of the brine pumped storage follows the same logic as water pumped storage and is related for utilization of energy from renewables [16] and performing energy arbitrage [17]. The role of energystorage system for integration of RES was investigated for the wind power [18], [19], [20] and the PV [21], [22]. Optimal design and techno-economic performance of solar-wind-pumped storage for power supply was presented in [23].

This paper is a continuation of the previous work where the impact of desalination on the penetration of renewables in a combination with brine operated pump storage was analysed for Jordan's current system [11] and possible scenarios for its development [15] . The results of the papers have shown that the utilization of a desalination and brine operated pump storage system could increase the penetration of wind power to $32 \%$ and $\mathrm{PV}$ to $37 \%$ in the current and the overall penetration of intermittent RES to $76 \%$ by 2050.

The contribution of this work is to investigate if the same or at least similar results can be obtained by using the new modelling approach which takes individual energy flows of the system as control variables that have to be optimized. The goal of this novel approach is to minimize the CEEP and increase the share of RES in the overall supply by optimizing system control variables for a longer period of time if optimization horizon $T$ is set to the values larger than one hour, which leads to better results in terms of reduction of CEEP. Increasing the $T$ above 24 hours makes no practical sense, since 
weather forecast and demand patterns are usuallyknown for one day in advance. Similar studies have already been performed for renewable microgrids with 24-hour uncertainty in environment variables [24], [25]. Although the impact desalination has on the economy of the overall energy system can be significant, it is not the topic of this paper and will not be discussed here. This impact has been demonstrated in our previous work [15].

\subsection{Problem formulation}

The energy system contains two demand streams: energy and fresh water. The problem scheme is presented in Figure 1.

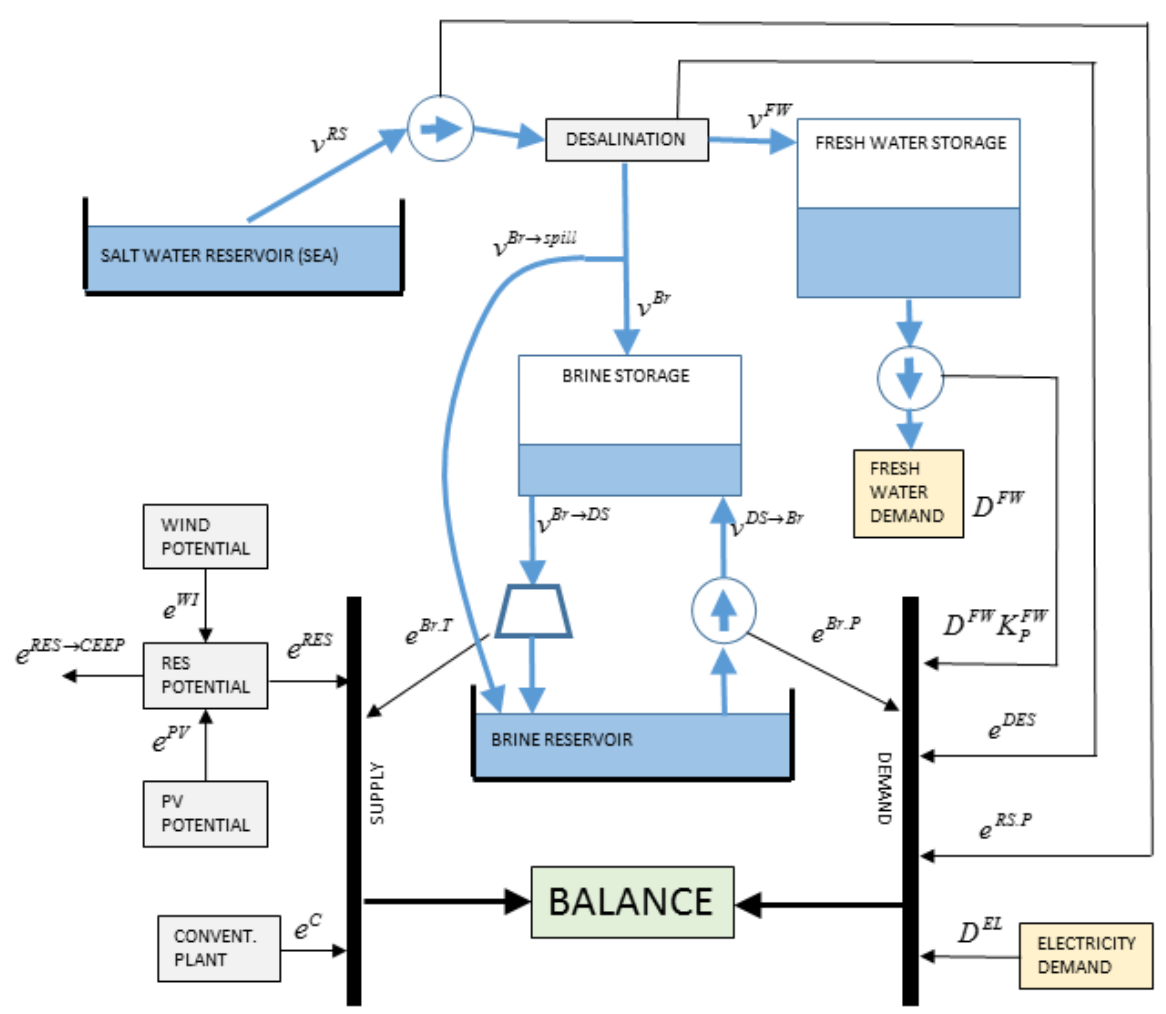

Figure 1. Problem formulation (energy system scheme), with all energy and volume flows as well as control variables

During the operation; the hourly demands of fresh water and electricity have to be fully satisfied. The supply of fresh water starts from pumping of the salt water into the desalination plant. Desalination plant produces fresh water and brine. Fresh water is stored in fresh water storage and brine is stored 
in brine storage. Brine storage is used as a pumped storage element in the overall energy system. Since all pumps, as well as the desalination plant, need energy for the operation, additional electricity demand is added to the initial demand. The energy produced from the installed capacities of wind, PV, brine turbine flow and the conventional power plants form the energy supply mix of the system.

Both storages, for fresh water and the brine, can be used to store excess electricity produced by the intermittent RES. This enables higher integration of renewables into the energysystem. However, only the brine storage can be used as pumped storage, while water storage stores the surplus of fresh water production from the desalination unit. Consequently, the amount of energy produced from the conventional plantsis reduced. Environment variables of the hourly distribution of electricity and fresh water demands, as well as distribution of available RES potential has to be known in advance which makes this problem fully deterministic, what is the usual approach in energy planning practice. In reality, environment variables are not exactly known in advance, but can be predicted, with reasonable accuracy and expectation, for no more than a single day in advance.

\section{Mathematical model}

The mathematical model is derived directly for the case study of Jordan, but can also be applied generally for any system involving the elements contained in this case. However, in ord er to present the model in the simplest and intuitive way, the terminology related to Jordan's case study is retained (Red sea and Dead sea).

\subsection{Objective function}

The objective function represents the function that summarizesall costs from the supplyand demand side and therefore it has to be minimized by finding the optimal set of control variables representing the vector of energy flows e.

The cost associated to each control variable is represented by the multiplication of a control variable and its specific cost $a_{t}^{X} e_{t}^{X}$, which means that the values of a determine the priority of supply scheme 
for a given system. The subscript $t$ means that all control variables are determined for a single discrete time step. The Objective function for the optimization horizon ranging from $t=1$ to $t=T$ can be written in the following form:

$f_{t=1 \rightarrow T}=\sum_{t=1}^{T}\left[\begin{array}{l}a_{t}^{R E S} e_{t}^{R E S}+a_{t}^{B r . T} e_{t}^{B r . T}+a_{t}^{C} e_{t}^{C}+ \\ +p_{t}^{E L} e_{t}^{B r . P}+p_{t}^{E L} e_{t}^{R S . P}+p_{t}^{E L} e_{t}^{D E S}+ \\ +a_{t}^{R E S \rightarrow C E E P} e_{t}^{R E S \rightarrow C E E P}\end{array}\right]$

Referring to the Eq. (1), the control variables are: supply from the renewable energy sources (RES) $e_{t}^{R E S}$, supply from the brine turbine flow $e_{t}^{B r . T}$, supply from the conventional power plants $e_{t}^{C}$, demand for pumping brine into brine storage $e_{t}^{B r . P}$, demand for salt water from the salt water reservoir $e_{t}^{R S . P}$, demand for desalination $e_{t}^{D E S}$, as well as producing critical excess of electricity production (CEEP) from the RES $e_{t}^{R E S \rightarrow C E E P}$. The CEEP is an excess in production of electricity that cannot be utilized with the simultaneous demand within the optimization time frame. The excess of production has to be immediately exported outside the system and it has to be driven to the lowest possible levels. In energy planning practice, it is usually set to $5 \%$ of the total annual electricity production [26] [27]. This CEEP limit represents the practical obstacle for larger integration of intermittent and non-flexible power sources, like renewables. The production of CEEP can be fully or partially offset by the use of different types of energy storage.

Detailed description of every component in the energy flow balance is described. Energy requiredfor pumping of the salt water into the desalination plant can be assumed to be proportional to the volume flow of the salt water:

$e_{t}^{R S . P}=K_{P}^{R S} v_{t}^{R S}$ 
Volume flow of salt water in the desalination plant is divided into volume flow of the fresh water and the residual brine water. The ratio between these two is determined by the ratio of desalination $X^{B}$ :

$$
\begin{aligned}
& v_{t}^{B r, t o t}=X^{B r}\left(v_{t}^{R S}\right) \\
& v_{t}^{F W}=\left(1-X^{B r}\right)\left(v_{t}^{R S}\right)
\end{aligned}
$$

Brine volume flow is further divided into the volume flow that can be taken by the brine storage and volume flow that has to be bypassed into the brine reservoir.

$v_{t}^{B r, t o t}=v_{t}^{B r}+v_{t}^{B r, s p i l l}$

Generally, the bypass to brine reservoir should be avoided, if possible, since it represents a pure loss of potential energy of the brine. Therefore, brine volume flows are converted into control variables and added into the objective function.

The energy required for desalination is assumed to be only electric and proportional to the volume of the produced fresh water:

$e_{t}^{D E S}=X^{D E S}\left(v_{t}^{F W}\right)$

Energy required for desalination can also be written as a function of the demand for the salt water.

$$
e_{t}^{D E S}=\left[X^{D E S}\left(1-X^{B r}\right)\right]\left(v_{t}^{R S}\right)
$$


The Objective function can now be rewritten in the following form:

$$
f_{t=1 \rightarrow T}=\sum_{t=1}^{T}\left[\begin{array}{l}
a_{t}^{R E S} e_{t}^{R E S}+a_{t}^{B r . T} e_{t}^{B r . T}+a_{t}^{C} e_{t}^{C}+p_{t}^{E L}\left(e_{t}^{B r . P}+e_{t}^{R S . P+D E S}\right)+ \\
+a_{t}^{R E S \rightarrow C E E P} e_{t}^{R E S \rightarrow C E E P}+a_{t}^{B r} v_{t}^{B r}+a_{t}^{B r, s p i l l} v_{t}^{B r, s p i l l}
\end{array}\right]
$$

In Eq. (8) pumping of the red sea and desalination have been combined into a single control variable.

$$
e_{t}^{R S . P+D E S}=\left[K_{P}^{R S}+X^{D E S}\left(1-X^{B}\right)\right] v_{t}^{R S}
$$

Energy required for pumping brine frombrine reservoir back to brine storage, as well as energygained from turbining the brine into brine reservoir, can be calculated as proportional to the volume flow of the brine:

$$
e_{t}^{B r . P}=K_{P}^{B r} v_{t}^{B r . P}
$$

$$
e_{t}^{B r \cdot T}=K_{T}^{B r} v_{t}^{B r \cdot T}
$$

In this work; Renewable power produced by wind and PV units is combined into a single source named simply RES. Doing this reduces the number of control variables, since for each RES activity only one control variable will exist instead of two (for example a single variable $e_{t}^{R E S}$ can be used instead of two $e_{t}^{W}$ and $\left.e_{t}^{P V}\right)$. This reduces the number of variables that need to be optimized. The nominal potential of renewable energy that can be taken from the following wind and PV distributions $\delta_{t}^{W, P V}$ and nominal installed capacity $\bar{P}^{W, P V}$ : 


$$
P_{t}^{R E S^{\prime}}=\delta_{t}^{W} \bar{P}^{W}+\delta_{t}^{P V} \bar{P}^{P V}
$$

Energy from conventional (non-renewable, based on fossil fuels) energy sources is taken as unlimited. Hourly distributions of demands for fresh water $D_{t}^{F W}$ and electricity $D_{t}^{E L}$ are known in advance and represent two of the required input variables for the problem formulated here.

The Vector of the control variables is defined as:

$$
\{e\}_{t=1 \rightarrow T}=\left(e_{t}^{R E S}, e_{t}^{B t . T}, e_{t}^{C}, e_{t}^{B r . P}, e_{t}^{R S . P+D E S}, e_{t}^{R E S \rightarrow C E E P}, v_{t}^{B r}, v_{t}^{B r, s p i l l}\right)_{t=1 \rightarrow T}
$$

The total number of control variables is $T$ timeslarger than the number of control variables for a single hour.

\subsection{Constraints}

Constraints for the optimization procedure are related to the physical limitations of the system: maximum levels of all storages; maximum power and mass flow rates between system components; and given demand or available wind and solar power distributions.

Balance between the electricity supply and demand:

$e_{t=1 \rightarrow T}^{R E S}+e_{t=1 \rightarrow T}^{B r . T}+e_{t=1 \rightarrow T}^{C}-e_{t=1 \rightarrow T}^{B r . P}-e_{t=1 \rightarrow T}^{R S . P+D E S}=D_{t=1 \rightarrow T}^{E L}+D_{t=1 \rightarrow T}^{F W} K_{P}^{F W}$

Renewable energy potential can be distributed among the following control variables:

$$
e_{t=1 \rightarrow T}^{R E S}+e_{t=1 \rightarrow T}^{R E S \rightarrow C E E P}=P_{t=1 \rightarrow T}^{R E S}
$$


Maximum energy that can be taken from the RES:

$e_{t=1 \rightarrow T}^{R E S} \leq P_{t=1 \rightarrow T}^{R E S}$

Constraints for the two storages in the system are related to maximum volume flow rates that can be taken by the free volume of the storages. Maximumvolume flow that can be pumped into fresh water storage:

$\sum_{t=1}^{T}\left(v_{t}^{F W}\right) \leq\left(\bar{S}^{F W}-S_{t-1}^{F W}+\sum_{t=1}^{T} D_{t}^{F W}\right)$

The minimum volume flow that needs to be inserted into fresh water storage has to be sufficient for satisfying the fresh water demand:

$$
\sum_{t=1}^{T}\left(v_{t}^{F W}\right) \geq\left(\sum_{t=1}^{T} D_{t}^{F W}-S_{t-1}^{F W}\right)
$$

These expressions can be related to control variables (energy) by:

$$
\begin{aligned}
& \left(\left(1-X^{B r}\right) X^{D E S}+K_{P}^{R S}\right) \sum_{t=1}^{T}\left(e_{t}^{R S . P+D E S}\right) \leq\left(\bar{S}^{F W}-S_{t-1}^{F W}+\sum_{t=1}^{T} D_{t}^{F W}\right) \\
& -\frac{1-X^{B r}}{\left(\left(1-X^{B r}\right) X^{D E S}+K_{P}^{R S}\right)} \sum_{t=1}^{T}\left(e_{t}^{R S . P+D E S}\right) \leq-\left(\sum_{t=1}^{T} D_{t}^{F W}-S_{t-1}^{F W}\right)
\end{aligned}
$$


There is a limit for a volume flow through the pipe from desalination plant and fresh water storage:

$v_{t}^{F W} \leq v_{\max }^{F W}$

which can be expressed in terms of control variables:

$-\frac{1-X^{B r}}{\left(\left(1-X^{B r}\right) X^{D E S}+K_{P}^{R S}\right)} \sum_{t=1}^{T}\left(e_{t}^{R S . P+D E S}\right) \leq v^{F W}$

The Maximum volume flow that can be taken by brine storage from the desalination plant (related to the fresh water produced) and pumping the brine from brine reservoir is:

$\sum_{t=1}^{T}\left(-v_{t}^{B r \rightarrow D S}+v_{t}^{D S \rightarrow B r}+v_{t}^{B r}\right) \leq\left(\bar{S}^{B r}-S_{t-1}^{B r}\right)$

The maximum volume flow that can be turbined out of the brine storage is:

$\sum_{t=1}^{T}\left(+v_{t}^{B r \rightarrow D S}-v_{t}^{D S \rightarrow B r}-v_{t}^{B r}\right) \leq\left(S_{t-1}^{B r}\right)$

These expressions can also be related to control variables (energy):

$\sum_{t=1}^{T}\left(-\frac{e_{t}^{B r . T}}{K_{T}^{B r}}+\frac{e_{t}^{B r . P}}{K_{P}^{B r}}+v_{t}^{B r}\right) \leq\left(\bar{S}^{B}-S_{t-1}^{B}\right)$ 
$\sum_{t=1}^{T}\left(+\frac{e_{t}^{B r . T}}{K_{T}^{B r}}-\frac{e_{t}^{B r . P}}{K_{P}^{B r}}-v_{t}^{B r}\right) \leq\left(S_{t-1}^{B}\right)$

There is a power limit for brine turbine flow and brine pumping:

$e_{t}^{B r . T} \leq P_{T}^{B r}$

$e_{t}^{B r . P} \leq P_{P}^{B r}$

The brine produced from the desalination plant is divided into two streams, the first goes to brine storage while the other is directly bypassed into the Red Sea. The three volume flows are related in following constraint:

$v_{t}^{B r}+v_{t}^{B r, \text { spill }}-v_{t}^{B r, t o t}=0$

which can be rewritten as:

$v_{t}^{B r}+v_{t}^{B r, \text { spill }}-\frac{1-X^{B r}}{\left(\left(1-X^{B r}\right) X^{D E S}+K_{P}^{R S}\right)} e_{t}^{R S . P+D E S}=0$

Grid stabilization constraint is set according to the criteria that energy from the conventional power sources and from brine turbine flowshould cover some predetermined percentage of total electricity supply, according to the expression $e_{t}^{B t . T}+e_{t}^{C} \geq F_{\text {stab }} e_{t}^{T O T}$. The final form of the constraint is given by: 
$F_{\text {stab }}\left(e_{t}^{R E S}+e_{t}^{R E S \rightarrow C E E P}\right) \leq\left(1-F_{\text {stab }}\right)\left(e_{t}^{B t . T}+e_{t}^{C}\right)$

Additionally, lower bounds for all control variables are set to zero.

$e_{t}^{R E S}, e_{t}^{B r \cdot T}, e_{t}^{C}, e_{t}^{B r \cdot P}, e_{t}^{R S . P+D E S+F W \cdot P}, e_{t}^{R E S \rightarrow C E E P}, v_{t}^{B r}, v_{t}^{B r, s p i l l} \geq 0$

Equations represent set of constraints for optimization in time horizon $T$. By setting the $T=1 \mathrm{~h}$ the optimization procedure reduces to the commonly used merit-ordering approach.

\subsection{Solution procedure}

The solution of the problem is done by minimizing the objective function $f$, subject to inequality and equality constraints.

$\min f=\mathbf{a} \cdot \boldsymbol{e}$

s.t.

$\mathbf{A} \cdot \boldsymbol{e} \leq \mathbf{b}$

$\mathbf{A}_{\mathrm{eq}} \cdot \boldsymbol{e}=\mathbf{b}_{\mathrm{eq}}$

$\boldsymbol{e} \geq 0$

Vector a defines the order of the supply energy flows contained in vector $\mathbf{e}$ and a penalty for the brine spill. Matrices $\mathbf{A}$ and $\mathbf{A}_{\mathrm{eq}}$, together with vectors containing solution to the system $\mathbf{b}$ and $\mathbf{b}_{\mathrm{eq}}$, are assembled from the constraints. From the mathematical point of view, this is essentially the linear programming problem, since the mathematical model and constraint formulations are linear. In this work a standalone code was written in GNU Octave, which was also used for pre-and post-processing, while open source (Mixed-Integer) Linear Programming system LPSOLVE was used as a linear solver [28].

\section{Case study for Jordan}

Water consumption of Jordan is only $145 \mathrm{~m}^{3}$ per capita annually [29], which is less than a third of the established international water poverty line of $500 \mathrm{~m}^{3}$ per capita annually [30]. Water scarcity is a 
common issue in countries in the Middle East and North Africa [31]. Jordan is also facing issues when it comes to its energy system. Almost all of its primary energy comes from imported fossil fuels; with 5909 ktoe or $83.6 \%$ coming from crude oil or oil products, another 872 ktoe or $12.3 \%$ from natural gas while the remaining 283 ktoe or $4.1 \%$ represents renewables and electricity import in 2011. [32]. When it comes to electricity production $72 \%$ has been produced from oil and $27 \%$ from nat ural gas, while less than $1 \%$ came from renewables in the same year [32]. Jordan's annual fuel expense exceeds 3 billion USD which is approximately20\% of its GDP for the year 2011 [33]. All of the mentioned issues will only increase if certain steps aren't made, especially considering the increase of Jordan's population by $50 \%$ until the year 2030 [34]. At the same time the increase of electricity demand is predicted to be $7.4 \%$ annually by 2020 , according to its official energystrategy [35]. On the other hand, several studies have shown a high potential for the economically viable utilization of wind [36], [37] and solar power [36], [38], with the payback period for wind power being as low as 6 years [39] and for solar power as low as 2.3 years [40] in some cases. The benefits of combining wind power [41] and PV [42] with desalination plants have already been discussed by many authors.

\subsection{Setup}

For Jordan's case study the salt water reservoir is the Red Sea and the brine reservoir is the Dead Sea. The variations of RES penetration and associated storage sizes are investigated through various scenarios listed in Table 1. Levels of penetration are set by the maximum theoretical share of RES covering the total demand for initial electricity and fresh water supply, Eq. (31)

$$
X_{\%}^{R E S}=\frac{\sum_{t=1}^{8760} P_{t}^{R E S}}{\sum_{t=1}^{8760}\left(D_{t}^{R E S}+D_{t}^{F W} K_{P}^{F W}\right)} 100 \%
$$


$X_{\%}{ }^{\text {RES }}$ can correspond to wind $\left(X_{\%}{ }^{\text {wind }}\right)$ or $\mathrm{PV}\left(X_{\%}{ }^{P V}\right)$. The capacity of the brine storage was set according to the following equation:

$\bar{S}^{B r}=P_{t}^{B r} T^{B r} / K_{t}^{B r}$

In Eq. (32) the numerator represents the capacity, in energy units, of the bri ne storage expressedas the multiplication of the maximum turbining power and the expected time of turbining at maximum power. Since the brine storage is a central element for balancing renewable energy sources, the variation of its size is also investigated. Table 1 gives an overview for the simulated cases.

Table 1-Simulation scenarios set

\begin{tabular}{lllllll}
\hline variable & $T$ & $X_{\%}^{P V}$ & $X_{\%}^{\text {wind }}$ & $T^{B r}$ & $\bar{S}^{B r}$ & $\bar{S}^{F W}$ \\
& & & & & \\
\hline unit & {$[\mathrm{h}]$} & {$[\%]$} & {$[\%]$} & {$[\mathrm{h}]$} & {$\left[\mathrm{Mm}^{3}\right]$} & \\
& & & & & & 1.5 \\
\hline min. value & 1 & 0 & 0 & 0 & - & 0 \\
\hline step & 24 & 5 & 5 & 12 & - & \\
& & & & & & \\
\hline max. value & 48 & 50 & 50 & 60 & calculated according to Eq. (32) & 1.5
\end{tabular}

The setup of the system parameters is given in Table 2. 
Table 2-System parameters for Jordan case study

system element parameters

$\begin{array}{ccccccc}\text { pumps and turbines } & K_{p}^{R S} & K_{t}^{B r} & K_{p}^{B r} & K_{p}^{F W} & P_{t}^{B r} & P_{p}^{B r} \\ & {\left[\mathrm{kWh} / \mathrm{m}^{3}\right]} & {\left[\mathrm{kWh} / \mathrm{m}^{3}\right]} & {\left[\mathrm{kWh} / \mathrm{m}^{3}\right]} & {\left[\mathrm{kWh} / \mathrm{m}^{3}\right]} & {[\mathrm{MW}]} & {[\mathrm{MW}]} \\ 2.725 & 3.72 & 3.72 & 4.75 & 350 & 350\end{array}$

desalination plant

$X^{B r} \quad X^{D E S}$

$[\%] \quad\left[\mathrm{kWh} / \mathrm{m}^{3}{ }_{\mathrm{FW}}\right]$

$55 \quad 1.925$

\begin{tabular}{cc}
$F_{\text {stab }}$ & $v_{\max }^{F W}$ \\
{$[-]$} & {$\left[\mathrm{m}^{3} / \mathrm{h}\right]$} \\
0.3 & $9.76 \cdot 10^{4^{*}}$ \\
\hline
\end{tabular}

* - taken as 1.5 times of the maximum hourly demand for the fresh water demand

Demands for electricity and fresh water are given by their total annual levels, as well as their hourly distributions. According to the IEA [32], total annual electricity demand of Jordan for a reference year 2011 was 16.299 TWh. The distribution was provided by the Jordanian National Electric Power Company (NEPCO) [43]. According to [44], the projected annual fresh water demand is $570 \mathrm{Mm}^{3}$. Fresh water distribution is assumed to be constant throughout the year, resulting in a constant hourly demand of $0.0650 \mathrm{Mm}^{3}$ (corresponding to a constant value of $18 \mathrm{~m}^{3} / \mathrm{s}$ ). Hourly distributions of solar and wind potential are obtained from METEONORM [45]. The values for coefficients for pumping and turbining of the Red Sea and the brine $\left(K_{p}^{R S}, K_{t}^{B r}\right.$ and $K_{p}^{B r}$ ) are determined by the geographical elevations of reservoirs and volume flows for the case of Jordan. For the case of Jordan the elevations 
of the Red sea is at zero meters of altitude, desalination plant, as well as brine and fresh water storage are at $1000 \mathrm{~m}$, while Dead sea is at $-385 \mathrm{~m}$. Volume flow for Red sea is determined by the fresh water demand and desalination plant efficiency, and it's value is $40 \mathrm{~m}^{3} / \mathrm{s}$ in average (resulting in an average target value of $18 \mathrm{~m}^{3} / \mathrm{s}$ of fresh water). The efficiency of the pumps are taken as constant values in order to retain the linear programming framework. Moreover, changes in elevations of the brine storage free surface is neglected. Coefficient for the fresh water pump $K_{p}^{F W}$ is taken from a similar studies [11] [15] and corresponds to the need that target value of fresh water needs to be pumped by $310 \mathrm{MW}$ of power in order to reach the end consumers. Same studies have been used for approximation of desalination plant efficiency and energy consumption per unit of fresh water.

Values of the vector a are $(1,2,10,1,1,20,1,100)$. This configuration sets the order of priority for the energy supply: 1. use energy from RES, 2. use energy from brine turbine flow and 3. use energy from conventional. The values for pumping the brine and pumping the Red Sea with desalination (the $4^{\text {th }}$ and $5^{\text {th }}$ element) should be set to low values in order to use the pumped brine and desalination of salt water in regulation services. The production of CEEP is penalized ( $6^{\text {th }}$ element) by setting the highest value in energy supply mix. Bypassing of the brine directly into the Dead sea is also penalized, favouring the filling of the brine storage instead.

\subsection{Results and analysis}

In order to validate the mathematical model, the results for $T=1 \mathrm{~h}$ are compared with results from the well-referenced EnergyPLAN tool, which provides an hourly balancing time frame for the system under investigation. It also provides the desalination module needed for this case. The validation is followed by the results showing the influence of RES penetration and storage size on performance of the method presented in this work. The performance indicator is the relative reduction of CEEP between the $T=24 \mathrm{~h}$ and $T=1 \mathrm{~h}$. The comparison of annual energy flows is given next in order to identify the change in the supply mix when optimizations with $T=24 \mathrm{~h}$ and $T=48 \mathrm{~h}$ were applied. 
Finally, the analysis of the storage activity for a single scenario $\left(X_{\%}{ }^{R E S}=50 \%\right.$ and $\left.T^{B r}=12 \mathrm{~h}\right)$ is investigated.

\subsubsection{Comparison of results obtained for $T=1 \mathrm{~h}$ with results from the EnergyPLAN}

From the set of a single-hour optimization scenarios presented in the Chapter 3.1, four were also modelled in EnergyPLAN and results are compared to the results of optimisation presented in this work for $T=1 \mathrm{~h}$. These are the cases with wind and PV penetration of $50 \%$ for two grid stabilisation factors: $F_{\text {stab }}=0.0$ and $F_{\text {stab }}=0.3$. The former allows larger share of RES in the supply mix, while the latter requires that minimum of $30 \%$ in the total supply mix (including the CEEP from RES) has to be provided from the conventional power plants and brine turbine flow for the purpose of stabilizing the grid operation.
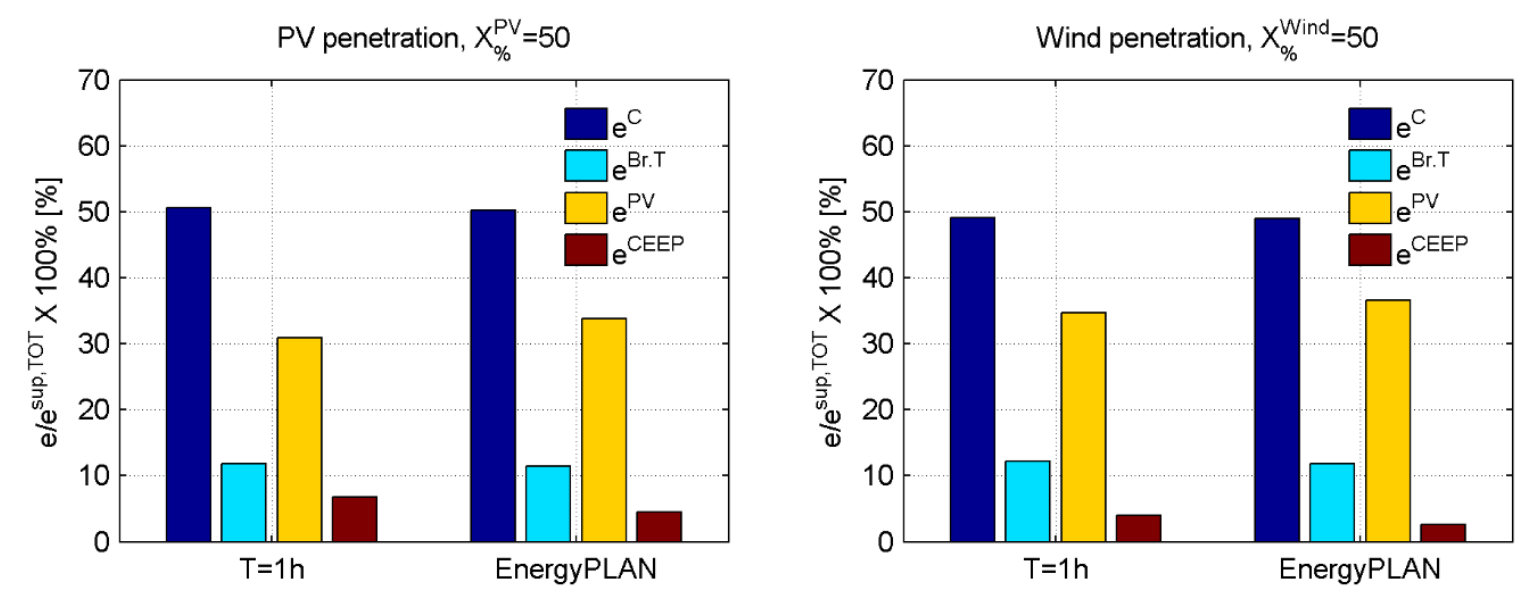

Figure 2 - Comparison of the annual mix of energy supply between optimization horizon $T=1 \mathrm{~h}$ and EnergyPLAN, case for $F_{\text {stab }}=0.0$ 

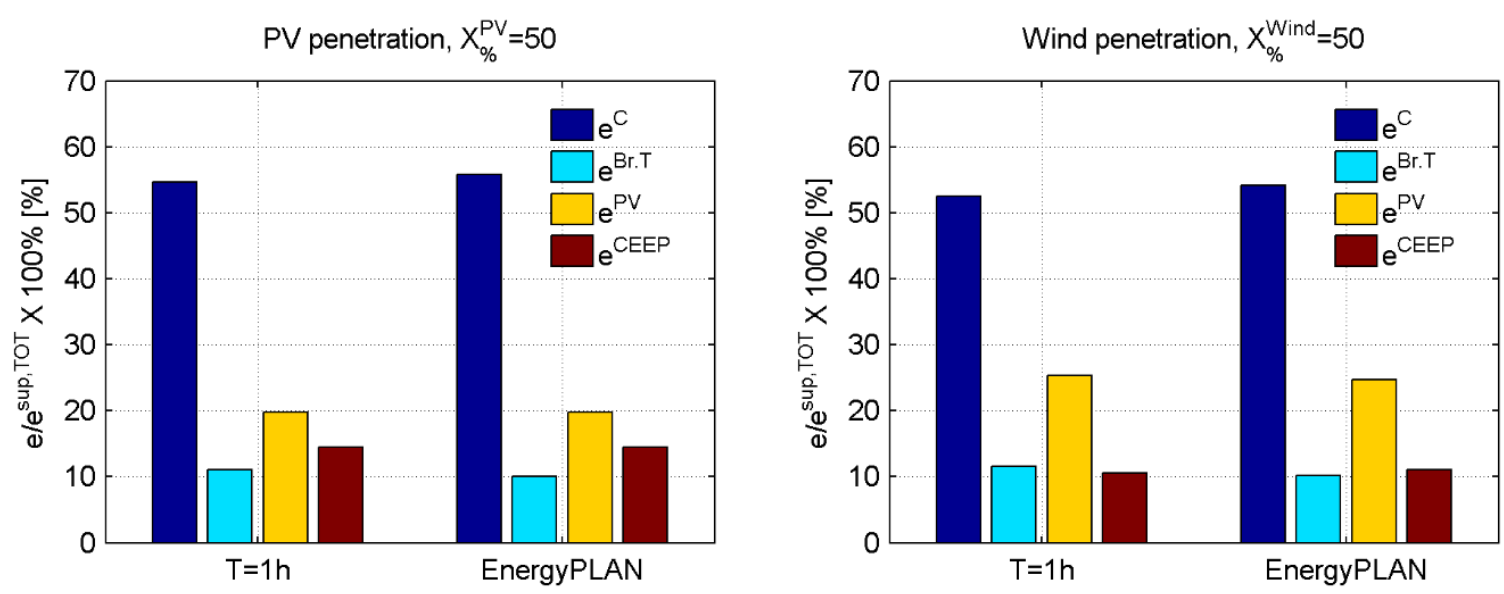

Figure 3 - Comparison of the annual mix of energy supply between optimization horizon $T=1 \mathrm{~h}$ and EnergyPLAN, case for $F_{\text {stab }}=0.3$

Results obtained by the method presented in this work are in good agreement with the results obtained from EnergyPLAN.

\subsubsection{Influence of the optimization horizon on CEEP reduction}

The differences between the cases of PV and wind penetration are influenced by the difference between the insolation and wind distribution, as well as their intermittency rates. Brine storage, as the crucial element responsible for the larger integration of renewables, is used for utilizing the excess of energy available from the intermittent sources. Regarding the storage size, too small storage may not be used for storing significant amounts of excess renewable energy, while too big storage could stay empty and unused. In this chapter the difference between the two optimizing horizons, one day ( $T=24 \mathrm{~h}$ ) and one hour $(T=1 \mathrm{~h})$ is investigatedfor each scenario presented in Table 1 . The differences are presented by comparing the annual values of CEEP, normalized by the results for $T=1 \mathrm{~h}$, as presented in the following equation: 
$\Delta E^{R E S \rightarrow C E E P} \frac{\sum_{t=1}^{8760}\left(e_{t}^{R E S \rightarrow C E E P}\right)_{T=24 h}-\sum_{t=1}^{8760}\left(e_{t}^{R E S \rightarrow C E E P}\right)_{T=1 h}}{\sum_{t=1}^{8760}\left(e_{t}^{R E S \rightarrow C E E P}\right)_{T=1 h}}$

Results for $\Delta E^{R E S \rightarrow C E E P}$ are presented in Figure 4 for $F_{\text {stab }}=0.0$ and Figure 5 for $F_{\text {stab }}=0.3$.
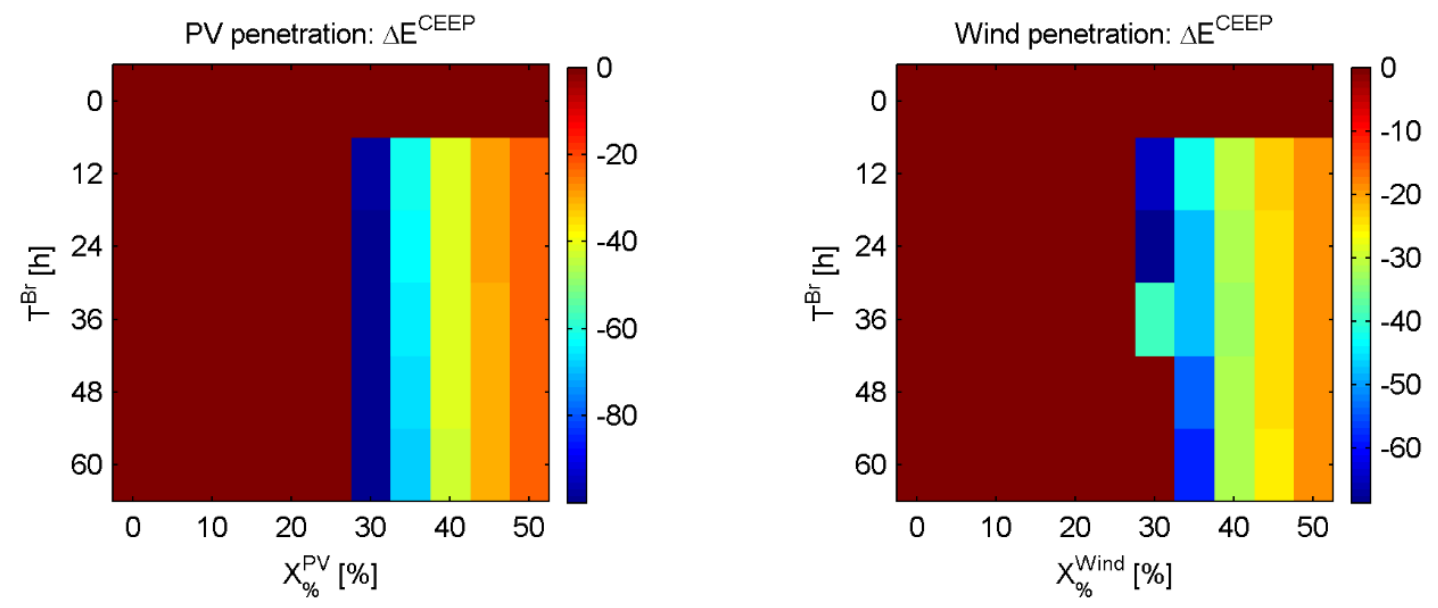

Figure 4 - Relative reduction of CEEP for different levels of RES penetration and sizes of the brine storage, case for $F_{\text {stab }}=0.0$
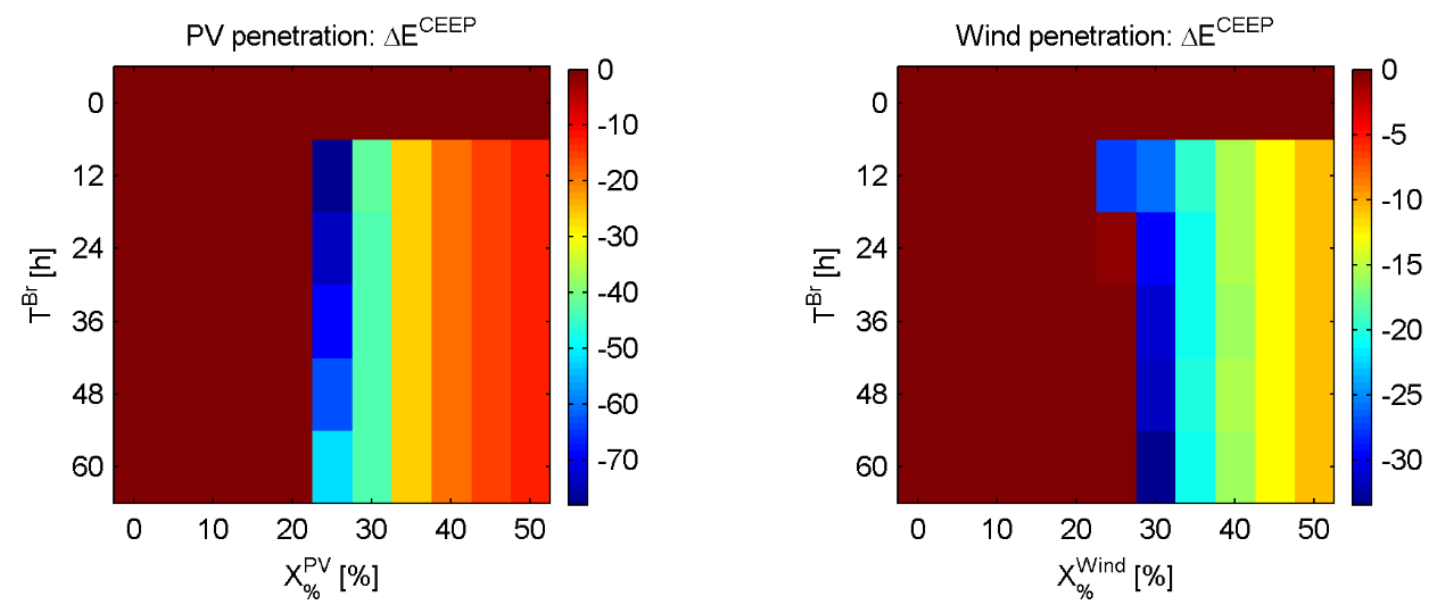

Figure 5 - Relative reduction of CEEP for different levels of RES penetration and sizes of the brine storage, case for $F_{\text {stab }}=0.3$ 
From the results presented in Figure 4 and Figure 5 it can be seen that the most significant reduction of CEEP is observed at the middle levels of PV and wind penetration (between $25 \%$ and $35 \%$ ), having values of $-100 \%$ and $-80 \%$ for PV penetration and $-70 \%$ and $-35 \%$ for wind penetration, depending on the grid stabilisation parameter. At this values of RES penetration the levels of CEEP are still very low and can be easily reduced by increasing the optimization horizon to $T=24 \mathrm{~h}$. By further increasing the RES penetration, the relative reduction of CEEP is lowered to approximately $-20 \%$ for $F_{\text {stab }}=0.0$ and

$-10 \%$ for $F_{\text {stab }}=0.3$. Generally, setting the grid stabilization to lower values decreases the CEEP values. By comparing the CEEP reduction with respect to the values of grid stabilization parameter, it can also be observed that reducing the grid stabilization also increases the potential for reducing the CEEP if optimization horizon increases to one day. Furthermore, the increase of the maximum brine storage capacity reduces the relative CEEP reduction for the case of PV penetration due to the fact that larger storage also reduces CEEP for $T=1 \mathrm{~h}$. Similar trend is observed for the cases of wind penetration.

\subsubsection{Influence of the optimization horizon on annual energy flows for $T^{B r}=$}

\section{$12 \mathrm{~h}$}

The annual energy analysis is performed in order to see the relative influence of increasing the optimization horizon $T$ on the annual energy flows of the energy supply. The results are presented for all levels of RES penetration and a single size of the brine storage corresponding to the $T^{B r}=12 \mathrm{~h}$. From the results presented in Figure 6 and Figure 7, increasing the optimization horizon leads to the decrease of annual levels of CEEP in the supply mix. The difference is most visible for the case of PV penetration and $F_{\text {stab }}=0.0$. However, the difference between $T=24 \mathrm{~h}$ and $T=48 \mathrm{~h}$ is not very big. The decrease of CEEP in the supply mix by employing the larger opti mization horizon can be significant and even increase the conclusion on the allowed limits for RES penetration. For example, the case for PV penetration and $F_{\text {stab }}=0.0$ shows that by increasing the optimization horizon from one to 24 hours 
can increase the allowable limit of the installed PV from approx. $45 \%$ to approx. $49 \%$ without exceeding the annual values of CEEP over the limit of $5 \%$.
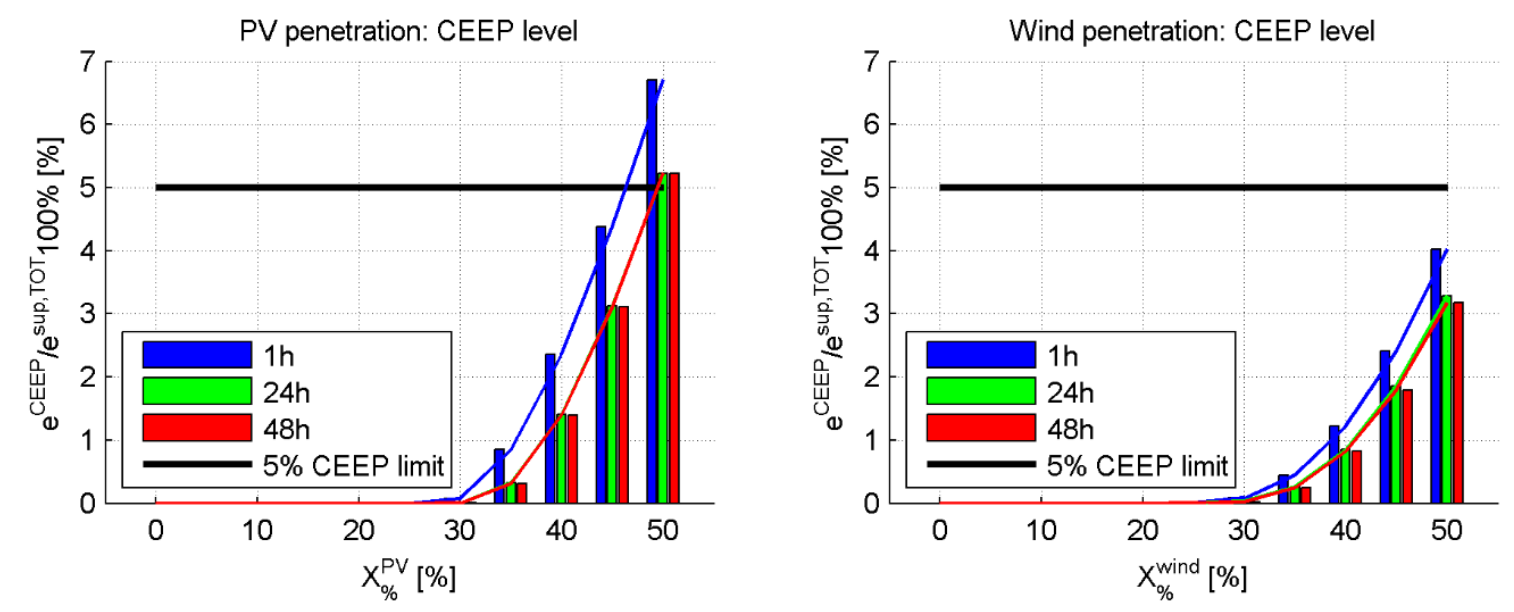

Figure 6 - Annual reduction of CEEP by increasing the optimization horizon for the cases of the PV and wind penetration and $F_{\text {stab }}=0.0$
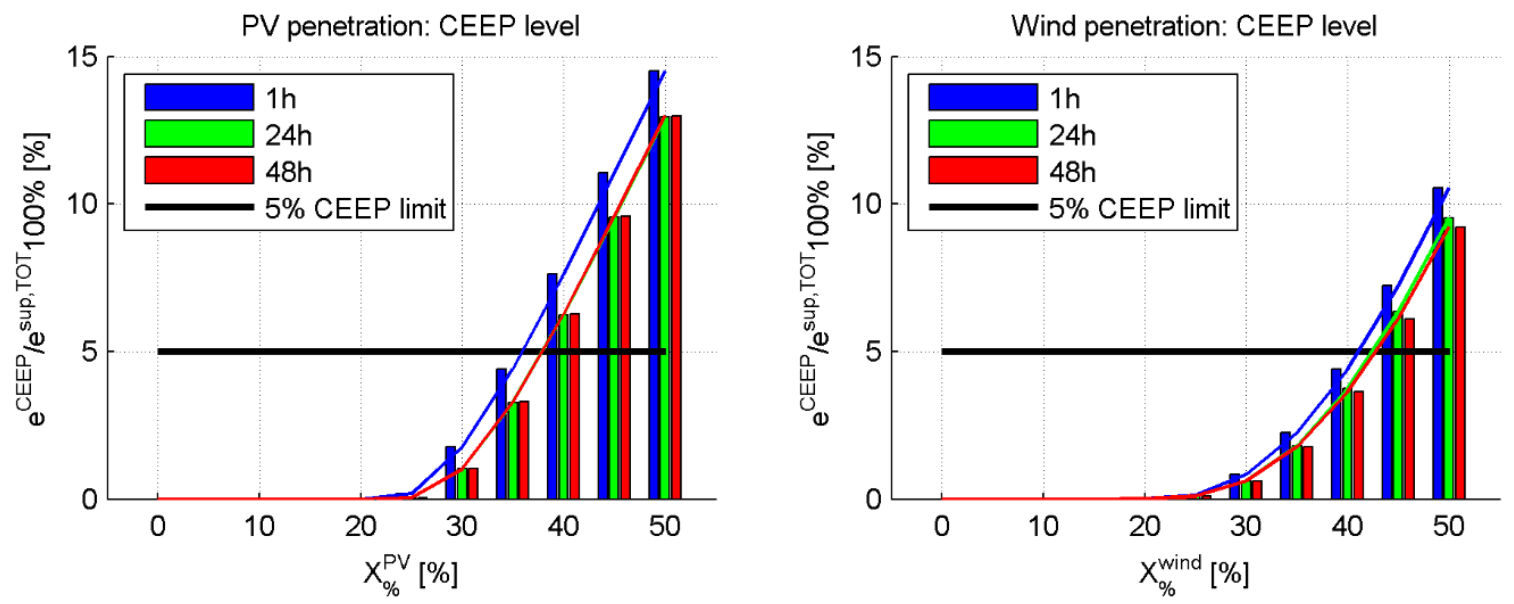

Figure 7-Annual reduction of CEEP by increasing the optimization horizon for the cases of the PV and wind penetration and $F_{\text {stab }}=0.3$

Differences between the annual energy mix for between the $T=24 \mathrm{~h}$ and $T=1 \mathrm{~h}$ are presented in Figure 8 for $F_{\text {stab }}=0.0$ and Figure 9 for $F_{\text {stab }}=0.3$. For both the PV and wind penetration same trends can be observed: energy flows optimized for one day horizon instead of one hour reduce the CEEP by 
the same amount as increase in RES production and decrease in production from conventional. Moreover, the increase in optimization time horizon is more meaningful for the reduction of CEEP for penetration of $\mathrm{PV}$ rather than wind.
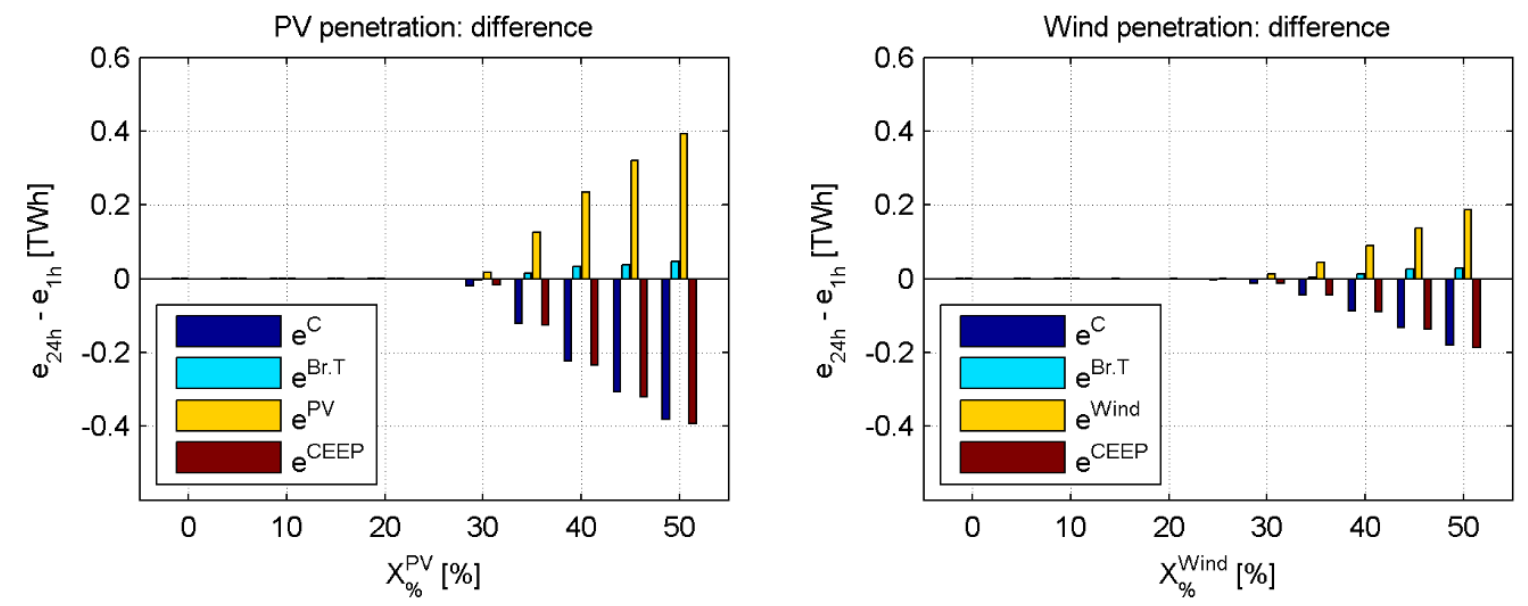

Figure 8 - Differences in annual energy flows between optimization horizons $T=24 \mathrm{~h}$ and $T=1 \mathrm{~h}$, case for $F_{\text {stab }}=0.0$
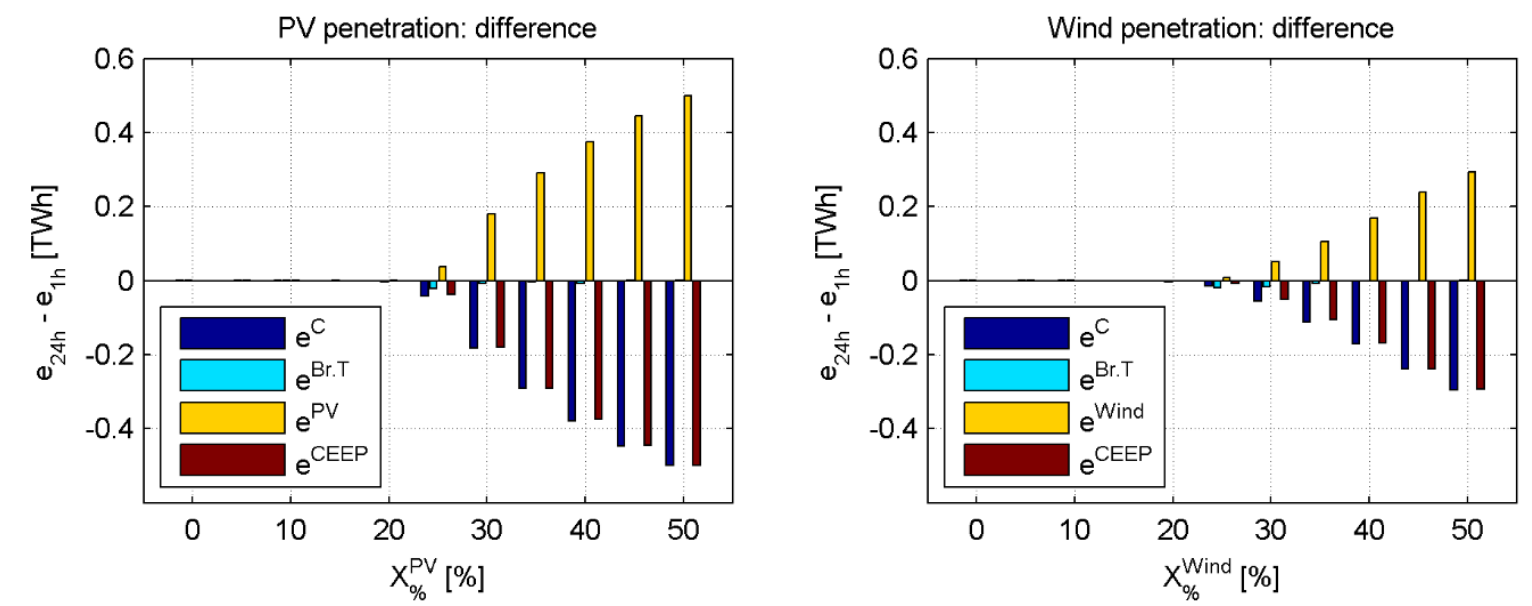

Figure 9 - Differences in annual energy flows between optimization horizons $T=24 \mathrm{~h}$ and $T=1 \mathrm{~h}$, case for $F_{\text {stab }}=0.3$ 


\subsubsection{Influence of the optimization horizon on storage activity for $X_{\%}^{R E S}=$}

\section{$50 \%$ and $T^{B r}=12 \mathrm{~h}$}

The influence of the optimization horizon on storage activity is important, since reduction of CEEP is directly proportional to the increased production from the RES which furthermore depends on the possibility for storing of the excess RES energy into the available storage capacities. Figure 10 presents time series of energy flows and storage levels for one week of the year, for the case of PV penetration. The difference between the storage levels of brine and fresh water is clearly visible and correlated to the available wind potential and reduction of CEEP. For the case of $T=24 \mathrm{~h}$ level of brine storage is lower prior to increase of PV potential. When PV potential rises, the excess energy from the RES production can be stored as potential energy of the brine in the brine storage. For the case of $T=1 \mathrm{~h}$ the level of the brine storage is too high in order to be able to store excess of the RES production. The role of the fresh water storage is only to take the excess of water production from the desalination plant and should be sufficiently large. 

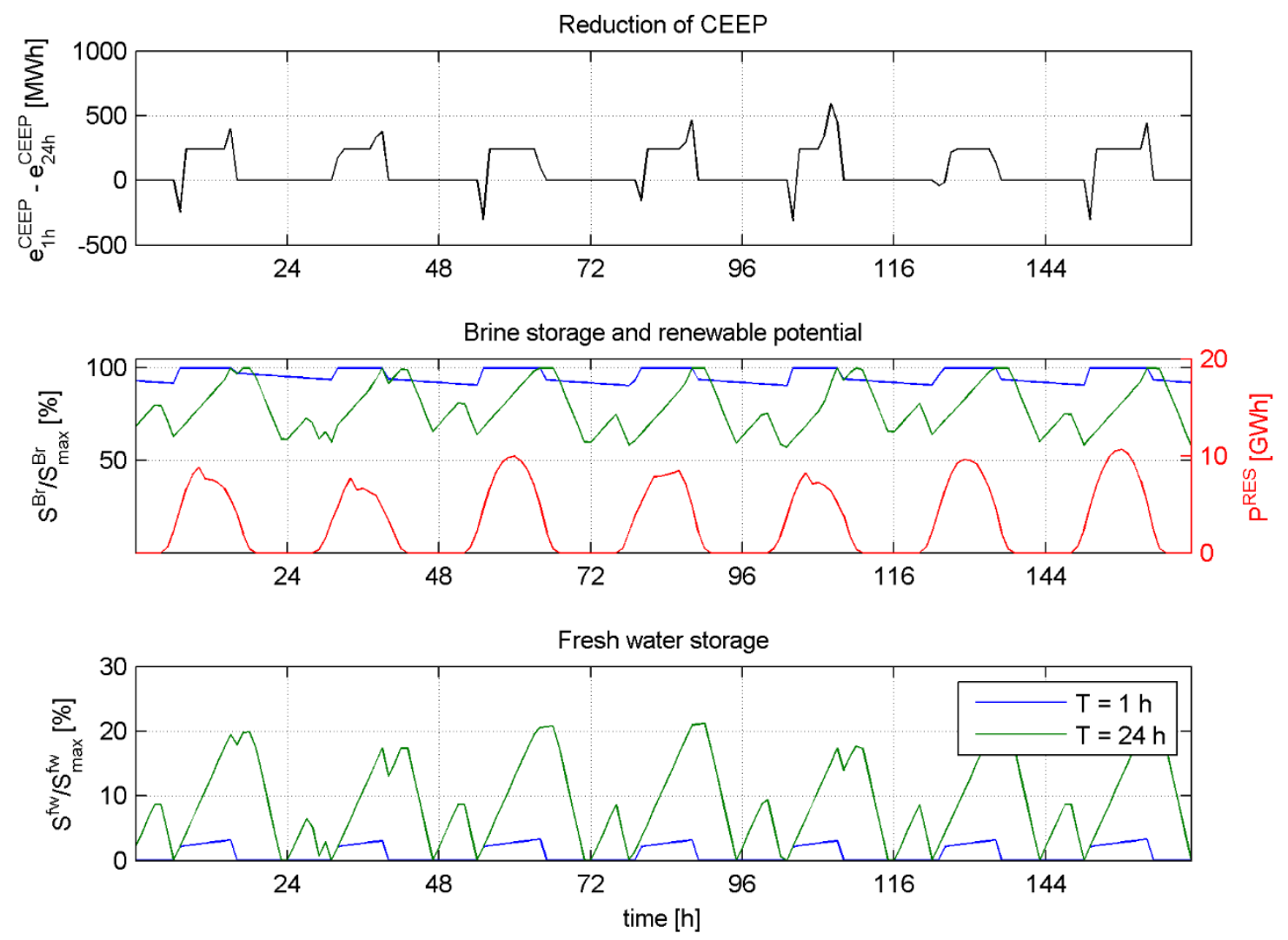

Figure 10-Time series of CEEP reduction, brine and fresh water storage and renewable potential

The activity of the brine storage can be presented by the scatter plots representing the difference between the filling rates for $T=24 \mathrm{~h}$ and $T=1 \mathrm{~h}$ with respect to the available RES potential. Scatter plots are presented in Figure 11 for $F_{\text {stab }}=0.0$ and Figure 12 for $F_{\text {stab }}=0.3$. 

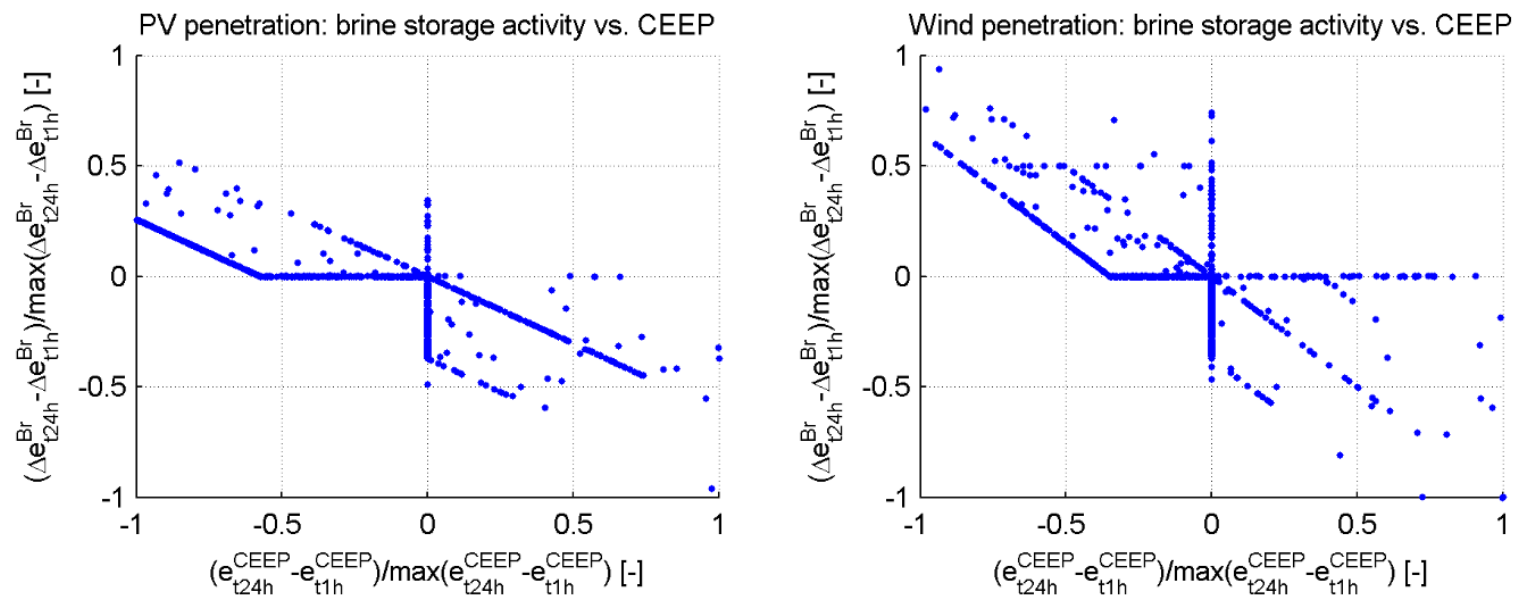

Figure 11 - Comparison of storage activity between the optimization horizons $T=24 \mathrm{~h}$ and $T=1 \mathrm{~h}$, case for $F_{\text {stab }}=0.0$
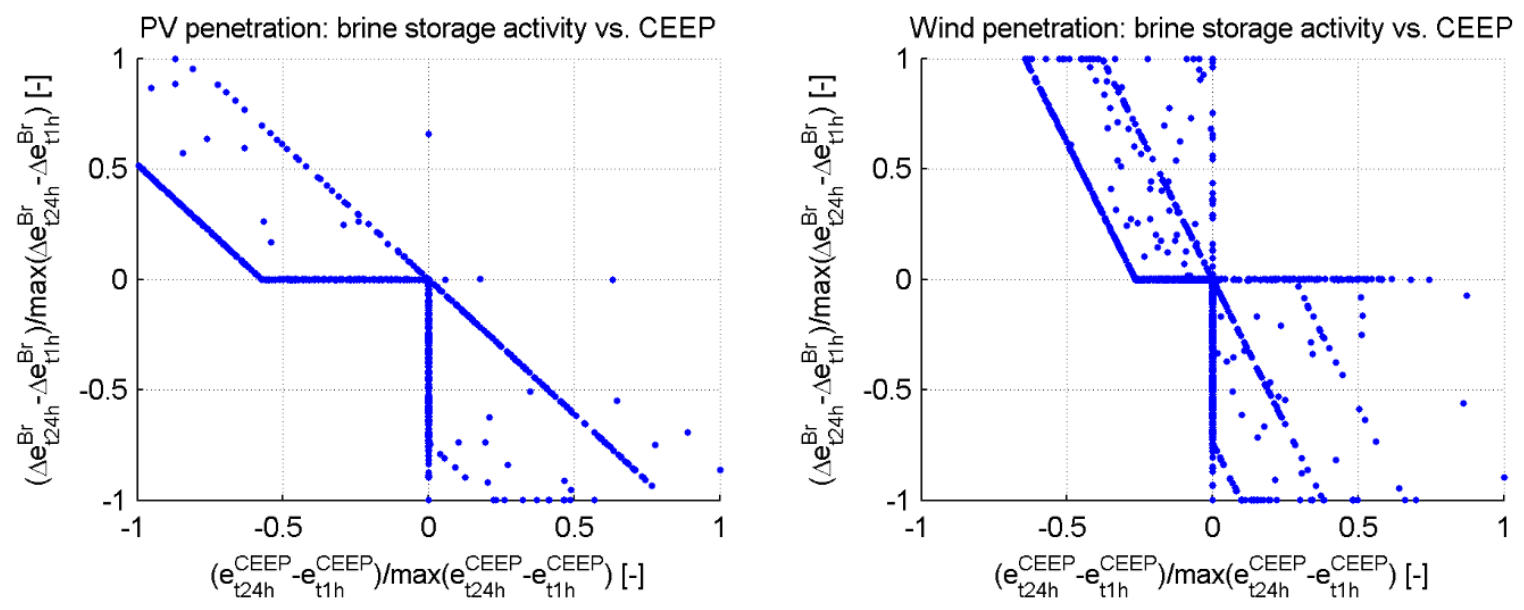

Figure 12 - Comparison of storage activity between the optimization horizons $T=24 \mathrm{~h}$ and $T=1 \mathrm{~h}$, case for $F_{\text {stab }}=0.3$

The results are showing that there is a strong negative correlation between the reduction in CEEP and net brine storage activity, expressed as $\Delta e^{B r}=e_{t}^{B r \cdot P}-e_{t}^{B r \cdot T}$, if $T=24 \mathrm{~h}$ is used over $T=1 \mathrm{~h}$. This can be explained by the fact that any excess of energy when $T=24 \mathrm{~h}$ is used to pump the brine from brine reservoir to brine storage. In this way the stored potential energy of the brine can be reused when there is a shortage of intermittent and cheap renewable energy.

\section{Conclusions}

This paper presents the optimization method for finding the optimal energy flowsin the systems with close integration of desalination and renewables. The presented method allows the use of 
optimization horizons larger than one hour, thus enabling better governance of the system in terms of CEEP reduction and increase in RES share in the supply mix. Results are showing that the new method provides results which are comparable with EnergyPLAN, if the optimization horizon is one hour. By increasing the optimization horizon to 24 hours and not changing either the system configuration or system environment variables, energy flows are changed in such a way that they provide lower values of CEEP and higher share of RES production in the supply mix. The crucial improvement in performance is a result of a better management of the brine storage as a central element for collecting the excess production from RES.

\section{Acknowledgement}

Financial support from the European Union's 7th Framework Programme managed by REA-Research Executive Agency (FP7/2007-2013) under Grant Agreement PIRSES-GA-2011-294933 (DISKNET project) and INCO-FP7 Specific Programme 'Capacities'- Horizontal actions and measures in support of international cooperation under Grant agreement number 266579 (JoRIEW project), is gratefully acknowledged.

\section{Bibliography}

[1] G. V. Gude, N. Nirmalakhandan and S. Deng, "Renewable and sustainable approaches for desalination," Renewable and Sustainable Energy Reviews, vol. 14, pp. 2641-2654, 2010.

[2] N. Ghaffour, S. Latteman, T. Missimer, N. K. Choong, S. Sinha and G. Amy, "Renewable energydriven innovative energy-efficient desalination technologies," Applied Energy, vol. 135, pp. 1155-1165, 2014. 
[3] M. Ammous and M. Chaabene, "Multi criteria sizing approach for Photovoltaic Thermal collectors supplying desalination plant," Energy Conversion and Management, vol. 94, p. 365376, 2015.

[4] G. V. Gude and N. Nirmalakhandan, "Sustainable desalination using solar energy," Energy Conversion and Management, vol. 51, no. 11, p. 2245-2251, 2010.

[5] S. Latterman, Development of an environ impact assesment and decision support system for seawater desal plants (PhD thesis), CRC press/Balkema, 2010.

[6] G. V. Gude, "Desalination and Sustainability - An Appraisal and Current Perspective," Water research, p. in press, 2015.

[7] G. Gude, "Energy storage for desalination processes powered by renewable energy and waste heat sources," Applied Energy, vol. 137, pp. 877-898, 2015.

[8] H. Sayyaadi and A. Saffari, "Thermoeconomic optimization of multi effect distillation desalination systems," Applied Energy, vol. 87, pp. 1122-1133, 2010.

[9] P. Druetta, P. Aguirre and S. Mussati, “Optimization of Multi-Effect Evaporation desalination plants," Desalination, vol. 311, pp. 1-15, 2013.

[10] A. Date, L. Gauci, R. Chan and A. Date, "Performance review of a novel combined thermoelectric power generation and water desalination system," Renewable energy, vol. 83, no. 1, pp. 256-269, 2015.

[11] T. Novosel, B. Ćosić, G. Krajačić, N. Duić, T. Pukšec, M. Mohsen, M. Ashhab and A. Ababneh, "The influence of reverse osmosis desalination in a combination with pump storage on the penetration of wind and PV energy: A case study for Jordan," Energy, vol. 76, pp. 73-81, 2014. 
[12] E. Mokheimer, A. Sahin, A. Al-Sharafi and A. Ali, "Modeling and optimization of hybrid windsolar-powered reverse osmosis water desalination system in Saudi Arabia," Energy Conversion and Management, vol. 75, pp. 86-97, 2013.

[13] P. Byrne, L. Fournaison, A. Delahaye, Y. Oumeziane, L. Serres, P. Loulergue, A. Szymczyk, M. Mugnier, J.-L. Malaval, R. Bourdais, H. Gueguen, O. Sow, J. Orfi and T. Mare, "A review on the coupling of cooling, desalination and solar photovoltaic systems," Renewable and Sustainable Energy Reviews, vol. 47, no. 1, pp. 703-717, 2015.

[14] T. Novosel, G. Gasparović, B. Ćosić, M. Mustafa, G. Krajačić, T. Pukšec and N. Duić, "Integration of Desalination and Renewables, a Demonstration of the Desalination Module in the H2RES Model: Case Study for Jordan," Chemical Engineering Transactions, vol. 34, pp. 355-360, 2014.

[15] T. Novosel, B. Ćosić, T. Pukšec, G. Krajačić, N. Duić, B. Mathiesen, H. Lund and M. Mustafa, "Integration of renewables and reverse osmosis desalination - Case study for the Jordanian energy system with a high share of wind and photovoltaics," Energy, Vols. in Press, Corrected Proof, 2015.

[16] D. Connoly, H. Lund, B. Mathiesen, E. Pican and M. Leahy, "The technical and economic implications of integrating fluctuating renewable energy using energy storage," Renewable Energy, vol. 43, pp. 47-60, 2012.

[17] C. Crampes and M. Moreaux, "Pumped storage and cost saving," Energy Economics, vol. 32, no. 2 , pp. 325-333, 2010.

[18] H. Zhao, Q. Wu, S. Hu, H. Xu and C. N. Rasmussen, "Review of energy storage system for wind power integration support," Applied energy, vol. 137, pp. 545-553, 2015. 
[19] A. Foley, P. Leahy, K. Li, E. J. McKeogh and A. P. Morrison, "A long-term analysis of pumped hydro storage to firm wind power," Applied Energy, vol. 137, pp. 638-648, 2015.

[20] A. Tuohy and M. O'Malley, "Pumped storage in systems with very high wind penetration," Energy Policy, vol. 39, no. 4, pp. 1965-1974, 2011.

[21] Zahedi, "Maximizing solar PV energy penetration using energystorage technology," Renewable and sustainable energy reviews, vol. 15, no. 1, pp. 866-870, 2011.

[22] T. Ma, H. Yang, L. Lu and J. Peng, "Pumped storage-based standalone photovoltaic power generation system: Modeling and techno-economic optimization," Applied Energy, vol. 137, pp. 649-659, 2015.

[23] T. Ma, H. Yang, L. Lu and J. Peng, "Optimal design of an autonomous solar-wind-pumped storage power supply system," Applied Energy, 2014.

[24] A. Baziar and K.-F. A., "Considering uncertainty in the optimal energy management of renewable micro-grids including storage devices," Renewable Energy, vol. 59, pp. 158-166, 2013.

[25] E. Kuznetsova, C. Ruiz, Y.-F. Li and E. Zio, "Analysis of robust optimization for decentralized microgrid energy management under uncertainty," International Journal of Electrical Power \& Energy Systems, vol. 64, pp. 815-832, 2015.

[26] B. Ćosić, M. N., T. V., K. G. and N. Duić, “Increasing the renewable energy sources absorption capacity of the Macedonian energysystem," Journal of Renewable and Sustainable Energy, vol. 5, no. 4, 2013.

[27] I. Bjelić, N. Rajaković, Ć. B. and N. Duić, "Increasing wind power penetration into the existing Serbian energy system," Energy, vol. 57, pp. 30-37, 2013. 
[28] “Ip_solve," [Online]. Available: http://Ipsolve.sourceforge.net/. [Accessed 2014 12].

[29] N. Hadadin, M. Qaqish, E. Akawwi and A. Bdour, "Water shortage in Jordan - Sustainable solutions," Desalination, no. 250, p. 197-202, 2010.

[30] UNDP, “UNDP in Jordan," $2013 . \quad$ [Online]. Available: http://www.jo.undp.org/content/jordan/en/home/ourwork/environmentandenergy/in_dept h/. [Accessed 30 August 2014].

[31] M. Moser, F. Trieb and T. Fichter, "Potential of Concentrating Solar Power Plants for the Combined Production of Water and Electricity in MENA Countries," Journal of Sustainable Development of Energy, Water and Environment Systems, vol. 1, no. 2, pp. 122-140, 2013.

[32] IEA, “International Energy Agency - Report," 2014. [Online]. Available: http://www.iea.org/statistics/statisticssearch/report/?country=JORDAN\&product=Balances\& year=2011. [Accessed 24 July 2013].

[33] A. Al-Ghandoor, "Evaluation of energy use in Jordan using energy and exergyanalyses," Energy and Buildings, no. 59, pp. 1-10, 2013.

[34] "Jordan's Department of Statistics," [Online]. Available: http://www.dos.gov.jo/. [Accessed 25 January 2013].

[35] “Updated Master Strategy of Energy Sector in Jordan for the period (2007-2020)," Hashemite Kingdom of Jordan, 2007.

[36] Y. Anagreh, A. Bataineh and M. Al-Odat, "Assessment of renewable energy potential, at Aqaba in Jordan," Renewable and Sustainable Energy Reviews 14, p. 1347-1351, 2010. 
[37] E. S. Hrayshat, "Wind resource assessment of the Jordanian southern region," Renewable Energy 32, pp. 1948-1960, 2007.

[38] M. S. Al-Soud and E. S. Hrayshat, "A 50MW concentrating solar power plant for Jordan," Joumal of Cleaner Production 17, pp. 625-635, 2009.

[39] M. A. Alsaad, "Wind energy potential in selected areas in Jordan," Energy Conversion and Management 65, p. 704-708, 2013.

[40] E. S. Hrayshat, "Viability of solar photovoltaics as an electricity generation source for Jordan," Renewable Energy 34, pp. 2133-2140, 2009.

[41] B. Peñate, F. Castellano, A. Bello and L. García-Rodríguez, “Assessment of a stand-alone gradual capacity reverse osmosis desalination plant to adapt to wind power availability: A case study," Energy, vol. 36, pp. 4372-4384, 2011.

[42] D. Herold and A. Neskakis, "A small PV-driven reverse osmosis desalination plant on the island of Gran Canaria," Desalination, no. 137, pp. 285-292, 2011.

[43] “NEPCO,” [Online]. Available: www.nepco.com.jo. [Accessed 3112 2014].

[44] M. Beyth, "The Red sea and the Mediterranean-Deadsea canal project," Desalination, vol.214, pp. 364-370, 2007.

[45] “http://meteonorm.com/," [Online]. 
